\title{
Crímenes de guerra y grupos de delincuencia organizada: problemáticas desde el principio de congruencia y la competencia para su juzgamiento*
}

\author{
Dubán Rincón Angarita* \\ Recibido: 04 de julio de 2017 • Aprobado: 11 de abril de 2018 \\ https://doi.org/10.22395/ojum.v17n34a2
}

\begin{abstract}
RESUMEN
Aunque existen posturas teóricas dispares sobre la naturaleza de los grupos de delincuencia organizada que operan en la actualidad en Colombia, las reglas hermenéuticas de la jurisprudencia de la Corte Constitucional establecen que es posible que estas agrupaciones cometan delitos contra las personas y bienes protegidos por el derecho internacional humanitario (también DIH), es decir, crímenes de guerra. Respecto de estos delitos, la competencia por el factor objetivo —en su vertiente de la naturaleza del asunto— corresponde a los jueces penales del circuito especializado. No obstante, dado el carácter difuso de las relaciones entre la criminalidad organizada y el conflicto armado, no sería inusitado que el fiscal yerre en la determinación del nomen iuris y acuse por un crimen común, y no por un crimen de guerra. El artículo pretende responder a la pregunta de cuál es la solución que debe adoptarse en estos eventos. La propuesta que aquí se presenta es que el juez debe decantarse por la declaratoria de la nulidad a partir de la presentación del escrito de acusación, como forma de armonizar las garantías del procesado con los derechos de las víctimas.
\end{abstract}

Palabras clave: crimen organizado; crimen de guerra; conflicto armado interno; competencia por el factor objetivo; principio de congruencia; nulidad procesal.

\footnotetext{
Artículo de investigación derivado del proyecto en curso denominado Crimen organizado y conflicto armado en Colombia: aproximación a una comprensión jurídica, en el marco de las actividades del Grupo de Investigación Derecho, Estado y Ciudadanía, de la Facultad de Derecho y Ciencias Políticas de la Universidad La Gran Colombia — seccional Armenia_. Investigador principal: Dubán Rincón Angarita. Institución que financia la investigación: Universidad La Gran Colombia — seccional Armenia-.

* Abogado, Universidad Industrial de Santander, Bucaramanga, Colombia; magíster en Derecho con énfasis en Ciencias Penales y Criminológicas, Universidad Externado de Colombia, Bogotá, Colombia; candidato a doctor en Derecho, Universidad Externado de Colombia, Bogotá, Colombia. Profesor e investigador, Universidad La Gran Colombia, Armenia, Colombia. Correo electrónico: rinconangduban@miugca.edu.co. Orcid: http://orcid.org/0000-0002-2555-227X
} 


\title{
War crimes and organized crime groups: problems from the congruence principle and the competence for their judgment
}

\begin{abstract}
Although there are disparate theoretical positions on the nature of the organized crime groups currently operating in Colombia, the hermeneutical rules of the Constitutional Court's jurisprudence establish that it is possible for these groups to commit crimes against persons and property protected by international humanitarian law (also IHL), that is, war crimes. With respect to these crimes, the competence for the objective factor -in its aspect of the nature of the mattercorresponds to the criminal judges of the specialized circuit. However, given the diffuse nature of the relationship between organized crime and armed conflict, it would not be unusual for the prosecutor to lie in the determination of the nomen iuris and charge for a common crime, and not for a war crime. The article seeks to answer the question of what solution should be adopted in these events. The proposal presented here is that the judge should opt for the declaration of nullity from the presentation of the indictment, as a way of harmonizing the guarantees of the defendant with the rights of the victims.
\end{abstract}

Keywords: organized crime; war crime; internal armed conflict; competition for the objective factor; principle of congruence; procedural nullity.

\section{Crimes de guerra e grupos de delinquência organizada: problemáticas desde o princípio de congruência e a competência para seu julgamento}

\begin{abstract}
RESUMO
Embora existam posturas teóricas díspares sobre a natureza dos grupos de delinquência organizada que operam atualmente na Colômbia, as regras hermenêuticas da jurisprudência da Corte Constitucional estabelecem que é possível que essas agrupações cometam delitos contra as pessoas e bens protegidos pelo direito humanitário internacional (DHI), ou seja, crimes de guerra. Com respeito a esses delitos, a competição pelo fator objetivo - em sua vertente da natureza do assunto - corresponde aos juízes penais do circuito especializado. Não obstante, dado o caráter difuso das relações entre a criminalidade organizada e o conflito armado, não seria inusitado que o fiscal falhasse na determinação do nomen iuris e acusasse por um crime comum, e não por um crime de guerra. O artigo pretende responder à pergunta de qual é a solução que deve ser adotada nesses eventos. A proposta que se apresenta aqui é que o juiz deve se inclinar pela declaratória da nulidade a partir da apresentação do escrito de acusação, como forma de harmonizar as garantias do processado com os direitos das vítimas.
\end{abstract}

Palavras-chave: crime organizado; crime de guerra; conflito armado interno; competição pelo fator objetivo; princípio de congruência; nulidade processual. 


\section{INTRODUCCIÓN}

El Título II del Código Penal colombiano, contentivo de los delitos contra las personas y bienes protegidos por el derecho internacional humanitario, es una de las herramientas con que cuenta el sistema jurídico en orden a la prevención y sanción de los crímenes de guerra, conductas que desde los instrumentos internacionales - especialmente el derecho de La Haya, el derecho de Ginebra y el Estatuto de Roma de la Corte Penal Internacional- se asumen como merecedoras de un especial reproche de lesividad, por el desconocimiento de las normas mínimas para la humanización de los conflictos armados (Salmón, 2012).

No obstante, la aplicación efectiva de los tipos penales que tipifican crímenes de guerra encuentra dificultades en aquellas figuras criminales que guardan relación con comportamientos punibles de criminalidad común, pero que se diferencian por la consagración de un sujeto pasivo calificado - persona protegida por el DIH - y el elemento de modo de la conducta - que el crimen sea cometido con ocasión y en desarrollo del conflicto armado - (Departamento Federal de Asuntos Exteriores, 2014).

A título de ejemplificación, compárese el delito de lesiones en persona protegida (artículo 136 del Código Penal), frente al punible de lesiones personales (artículos 111 y siguientes, éjusdem). El estudio de estas conductas arroja como semejanzas que el núcleo de la acción es el mismo (causar daño en el cuerpo o en la salud).
No obstante, el comportamiento de lesiones en persona protegida es un crimen de guerra, por el carácter especial del sujeto pasivo, y por el hecho de cometerse con ocasión y en desarrollo del conflicto armado. Si se carece de estos ingredientes, la conducta será de lesiones como crimen común.

Desde la perspectiva teórica no es excesivamente ardua la diferenciación entre los dos tipos de crimen. Con todo, existen dificultades prácticas para la tipificación, sobre todo por la verificación del componente modal de la conducta — que la acción se despliegue con ocasión y en desarrollo de conflicto armado- (Organización de las Naciones Unidas, 2011). No es tampoco sencilla la constatación relativa a que un determinado actor haya cometido un crimen de guerra. Este aserto se dificulta cuando se trata de grupos de criminalidad organizada. En muchas ocasiones no es claro si la actividad versó sobre un crimen común o se llevó a cabo una conducta en el marco del conflicto (Corte Constitucional, 2016a).

Ahora bien, de ello depende además el juez competente del proceso penal. De acuerdo con las reglas adjetivas, el único funcionario judicial facultado para conocer crímenes de guerra es el juez penal del circuito especializado, al tenor del numeral $4^{\circ}$ del artículo 35 de la Ley 906 de 2004. Puede suceder, entonces, que el proceso penal se sustanció frente a un delito común, y a su turno, se acusó bajo dicho crimen. Pero puede acontecer que en la etapa de juicio surjan claros elementos de convicción que permitan 
afirmar que el grupo de criminalidad organizada llevó a cabo un crimen de guerra, esto es, un delito contra las personas y bienes protegidos por el DIH. Aparecen, en consecuencia, problemáticas entre la competencia por el factor objetivo y el principio de congruencia en su vertiente jurídica.

Y se plantea que surgen inconvenientes respecto del principio de congruencia porque, al menos en principio, la conducta por la que debe condenarse o absolverse debe ser la misma por la que se elevó la acusación. Esta congruencia jurídica es, por tanto, una consonancia entre el pliego de cargos y la sentencia (Mendoza, 2009).

Por otra parte, la competencia para el juzgamiento de crímenes de guerra se encuentra radicada en el juez penal del circuito especializado. De forma que, si en un caso concreto, existe error en la calificación jurídica - se acusa por un crimen común cuando lo cierto es que se cometió un crimen de guerra-, la solución impacta necesariamente en la competencia por el factor objetivo (naturaleza del asunto). Por tanto, es justo preguntar: ¿Cuál es la actuación que debe realizarse? ¿Cuál es el procedimiento más acorde con el contexto de la jurisprudencia constitucional y los derechos de las víctimas?

De esta manera se motiva el problema de investigación del presente artículo, que se remite al siguiente interrogante: ¿Cuál es la solución que debe adoptarse por parte del juez, cuando en un proceso sustanciado respecto de un crimen común cometido por miembros de grupos de delincuencia organizada aparecen claros elementos de convicción que señalan que se trata de un crimen de guerra? Por consiguiente, el objetivo general del artículo es el de establecer la solución que debe adoptarse por parte del juez, en los eventos en los que en un proceso sustanciado respecto de un crimen común cometido por miembros de grupos de delincuencia organizada aparecen claros elementos de convicción que señalan que se trata de un crimen de guerra.

La investigación se justifica desde diversas esferas: en primer término, desde la necesidad de profundizar en el entendimiento de las relaciones existentes entre la criminalidad organizada y el conflicto armado en Colombia. En segundo término, desde la necesidad de brindar una respuesta oportuna a los eventos en los que existan errores o divergencias en la fijación del nomen iuris por el que se realiza el llamamiento a juicio del miembro del grupo de criminalidad organizada, sus relaciones con el principio de congruencia y la competencia por el factor objetivo por la naturaleza del asunto.

Metodológicamente, se trata de una investigación con alcance correlacional entre dos fenómenos: de una parte, las relaciones entre el crimen organizado y el conflicto armado. Y de otro lado, las respuestas procesales a los casos concretos en los que existan divergencias respecto de la definición de una conducta como crimen común o como crimen de guerra, y su impacto en el principio de congruencia y el factor objetivo de competencia en 
los delitos contra las personas y bienes protegidos por el derecho internacional humanitario. Asimismo, se trata de una investigación de carácter cualitativo, basada en la revisión de las fuentes primarias (normas jurídicas y pronunciamientos jurisprudenciales de la Corte Constitucional) y secundarias (principalmente artículos de investigación) sobre la materia.

El principal resultado que presenta el artículo es que en los casos en los que a partir de la etapa de acusación hubo yerro en la calificación jurídica de los hechos - pues se acusó por un crimen común cuando debió hacerse por un crimen de guerra-, y en los que es sujeto pasivo de la acción penal un miembro de un grupo de criminalidad organizada, la solución más ajustada a los criterios de los derechos de las víctimas ya la justicia material del caso concreto, es la declaratoria de la nulidad de la actuación a partir de la presentación del escrito de acusación, conforme la posibilidad que sobre el particular ofrece el artículo 456 del Código de Procedimiento Penal.

Al respecto, el plan de trabajo comienza por presentar una síntesis de las posturas teóricas en torno a la naturaleza de los grupos de criminalidad organizada en Colombia. A renglón seguido, se hace énfasis en las reglas interpretativas fijadas por la Corte Constitucional respecto de la noción amplia de conflicto armado y su relación con la comisión de crímenes de guerra.

Posteriormente, se presentan los institutos jurídicos del principio de congruencia y la competencia por el factor objetivo -naturaleza del asunto- en los eventos de crímenes de guerra. A partir de este marco, se presenta a continuación la tensión entre estos conceptos cuando se trata de error en la calificación jurídica. Seguidamente, se presentan las opciones con que cuenta el juzgador para resolver la problemática. Finalmente, se ofrece la que desde este escrito se asume como la solución adecuada a la problemática: la declaratoria de nulidad a partir de la presentación del escrito de acusación.

\section{DIVERGENCIAS TEÓRICAS EN TORNO A LA NATURALEZA DE LOS GRUPOS DE CRIMINALIDAD ORGANIZADA EN COLOMBIA}

No ha sido pacífico el desarrollo teórico en cuanto a la toma de postura respecto de si los grupos de criminalidad organizada en Colombia tienen la calidad de actores armados del conflicto interno (Corte Constitucional, 2012a). ¿Es su principal actividad la comisión de crímenes de guerra? ¿Dificulta la problemática el hecho de que hayan recibido numerosas denominaciones, como la de bandas criminales, neoparamilitares o grupos post desmovilización? (Rico, 2013).

Esta multiplicidad de enfoques se afinca especialmente en las discrepancias en torno al análisis de la naturaleza de los grupos que en la actualidad perfilan la criminalidad organizada en Colombia. Este interrogante tiene mucho que ver con la pregunta de si son los herederos y continuadores de la actividad paramili- 
tar en la escena criminal del país (Arias, 2011). La revisión de las fuentes sobre la materia permite concluir que existen tres posiciones sobre el particular:

Para una primera posición, los grupos de delincuencia organizada que operan en la actualidad son, en efecto, herederos de las facciones paramilitares existentes con anterioridad al proceso de desmovilización. En este sentido, aunque se haya surtido el proceso de dejación de las armas, el mismo no implicó el desmonte de las estructuras criminales ancladas a los negocios ilícitos de los paramilitares, especialmente el narcotráfico (Pérez y Montoya, 2013). En consecuencia, quienes otrora fueran mandos medios o miembros de las agrupaciones paramilitares retomaron el control, empleando los mismos métodos de la intimidación, la corrupción y la violencia para la consecución de sus fines. Para ello, aprovecharon las redes de contactos ya existentes y el control de ciertas zonas geográficas estratégicas (Granada, Restrepo y Tobón, 2009). De ahí que sea acertado estudiarlos como grupos herederos del accionar paramilitar en Colombia. Para Prieto (2013), "la realidad muestra que estas bandas surgieron en regiones donde previamente existía presencia paramilitar y continuaron las prácticas de control social, incluida la violencia contra líderes comunitarios y otros grupos vulnerables" (p. 9).

Por estas razones, serían más atinadas las nociones de "neoparamilitares", "paramilitares de tercera generación" o "grupos post desmovilización" (Arias, 2011). A partir de estas denominaciones se refiere también su naturaleza de ser herederos del actuar paramilitar. En este orden, el proceso de desmovilización no significó el efectivo desmonte de la estructura del aparato de guerra implementado por los grupos paramilitares (Granada, Restrepo y Tobón, 2009, p. 468).

Es de resaltar que, en muchos casos, la desmovilización fue meramente aparente, aserto que se constata si se considera que muchos cabecillas y miembros de las Bacrim fueron jefes de rango medio de las AUC que nunca se desmovilizaron, o que aparentaron sumarse a la desmovilización (Comisión Interamericana de Derechos Humanos, 2013). Por esta razón, para otras fuentes, el fenómeno de las bandas criminales debe continuar evaluándose como paramilitarismo (Amnistía Internacional, 2016). Ahora bien, el debate en torno a la naturaleza de las agrupaciones de criminalidad organizada tiene importancia a la hora de determinar la posibilidad de comisión de crímenes de guerra en el marco del conflicto armado.

En efecto, si se afirma que los grupos de crimen organizado son continuadores del paramilitarismo, es poco problemático sostener que sus conductas pueden llegar a constituir crímenes de guerra. En este orden, puede sostenerse que, si las agrupaciones paramilitares podían ser sujetos activos de delitos contra las personas y bienes protegidos por el derecho internacional humanitario, esto es, delitos cometidos con ocasión y en desarrollo del conflicto armado, los continuadores de su actividad, es decir, los grupos de criminalidad organizada, pueden asimismo 
llevar a cabo delitos contra las personas y bienes protegidos por el derecho internacional humanitario.

Para una segunda posición, que tradicionalmente ha sido la posición oficial, especialmente durante el mandato del presidente Uribe Vélez (Echandía, 2013), el fenómeno paramilitar finiquitó con el proceso de desmovilización, y las agrupaciones de criminalidad organizada no tienen que ver con los grupos de autodefensas.

En este sentido, aunque se trate de organizaciones criminales, sus actividades no son la continuación del accionar paramilitar en Colombia, sino que evolucionan a partir del crimen organizado, que se guía en esencia por el afán de lucro de los criminales (Kessler, 2014). En consecuencia, es más acertado denominar estas agrupaciones como "bandas criminales", nombre con el que se toma distancia respecto del accionar paramilitar. De acuerdo con la Comisión Interamericana de Derechos Humanos (2013), oficialmente "se reconoce que algunos paramilitares desmovilizados han retomado la actividad delincuencial; pero insiste en que no hay continuidad organizativa entre los grupos paramilitares y las Bacrim" (p. 1).

La naturaleza de los grupos de criminalidad organizada, por tanto, no obedece a la continuación de la actividad paramilitar. Proviene del aprovechamiento de los vacíos de poder dejados por estos grupos, ocupados ahora por la criminalidad organizada. Este fenómeno es especialmente evidente respecto del control del negocio del tráfico de drogas. Para
Garzón (2008), tuvo lugar el reacomodo de la escena criminal en Colombia a fin de continuar las actividades ilícitas. De acuerdo con Prieto (2012), "desde el punto de vista oficial se les asignó el nombre de bandas criminales con el propósito de darle identidad a aquellos grupos que surgieron tras la desmovilización de los grupos paramilitares ocurrida entre los años 2003 y 2006" (p. 183).

Este entendimiento tiene influencia en la determinación de la tipología de las actividades ilícitas de los grupos. Si se considera que las bandas criminales no son continuadoras de las actividades de los grupos de autodefensa, es problemático afirmar, sin más, que cometen crímenes de guerra. Por consiguiente, su accionar será más cercano a los delitos comunes.

Para una tercera posición, puede hablarse de una naturaleza "mixta" de las agrupaciones de criminalidad organizada en Colombia. Si bien algunos de los grupos son claramente herederos de la estructura, las estrategias de control y el modo de operar de los paramilitares, otras agrupaciones ya operaban en el momento de la desmovilización, no ostentaban intereses contrainsurgentes y se dedicaban al crimen organizado. Igualmente, otras nacieron a medida que se evidenciaba el vacío de poder dejado por los grupos paramilitares (Granada, Restrepo y Tobón, 2009).

Por ejemplo, para Echandía (2013), "la dimensión contrainsurgente no fue el objetivo central de los grupos desmovilizados $y$, por lo tanto, las bandas del presente 
tienen continuidad con las organizaciones que han existido en el país en los últimos treinta años en estrecha relación con el narcotráfico" (p. 5). Ante la heterogeneidad de esta composición, "no es pacíficamente aceptado que se trate de una nueva generación de paramilitarismo" (Latorre Iglesias y Arregocés, 2014, p. 263).

Así las cosas, puede hablarse de una naturaleza multicausal de los grupos de criminalidad organizada. Algunos serán continuadores de los paramilitares, y otros no (Granada, Restrepo y Tobón, 2009). En este sentido, y para el tema que ocupa este escrito, habrá de estudiarse en cada caso concreto la actividad de la organización a fines de determinar si lo cometido es un crimen común o un crimen de guerra (Corte Constitucional, 2012b).

En este escrito se toma posición favorable a este entendimiento multicausal del crimen organizado. Se trata de dos grandes fenómenos que convergen, y cada uno muestra una enorme complejidad: en primer lugar, el conflicto armado, con aristas difusas y variables, de un lado, y el crimen organizado, que por naturaleza tiende a ser subrepticio, pero que basa buena parte de su actividad en el ejercicio de la violencia, del otro (Kessler, 2014). De esta forma puede explicarse buena parte del paralelismo entre ambos fenómenos.

Así, desde una perspectiva ex ante, es imposible asumir que un grupo de criminalidad organizada comete crímenes de guerra. Habrá de establecerse, en concreto, y caso por caso, si la actividad del grupo de criminalidad organizada tuvo lugar con ocasión y en desarrollo del conflicto armado (Corte Constitucional, 2012b).

Otro argumento de relevancia es que los tipos penales que consagran los crímenes de guerra no demandan un sujeto activo calificado. Así, y al menos en principio, cualquier persona puede ser sujeto activo de crímenes de guerra (Defensoría del Pueblo, 2014). Se requerirá, por supuesto, de la verificación de los demás ingredientes de esta forma de criminalidad, especialmente el carácter calificado del sujeto pasivo y el elemento modal de la conducta.

\section{LAS REGLAS DE HERMENÉUTICA CONSTITUCIONAL SOBRE LA COMISIÓN DE CRIMENES DE GUERRA POR PARTE DE LAS AGRUPACIONES DE CRIMEN ORGANIZADO}

Las líneas jurisprudenciales de la Corte Constitucional sobre este aspecto se han inclinado por el análisis caso por caso. Esto es, en virtud de la complejidad del conflicto armado, deberá estudiarse en cada evento si la conducta constituye un crimen común o un crimen de guerra. Es de reseñar que esta interpretación de la Corte hace eco de las directrices del derecho internacional humanitario, y que la labor de la Corte es la de aplicar esta preceptiva para el caso colombiano. Los pronunciamientos sobre el particular han destacado ciertas categorías:

En primer término, debe patrocinarse una interpretación amplia de la expresión "con ocasión del conflicto armado interno". Este ingrediente implica un amplio abanico de circunstancias en las que 
la conducta punible puede presentarse (Corte Constitucional, 2017). Para la Corte, las infracciones al derecho internacional humanitario tienen origen, entre otras causas, en la actividad de actores armados con estructura militar o dominio territorial, en tanto consecuencia de acciones relacionadas de forma cercana y suficiente con el conflicto armado (Corte Constitucional, 2012b).

El segundo criterio a tener en cuenta es la noción amplia de conflicto armado. De acuerdo con la Corte, se trata de aquel que "reconoce toda la complejidad real e histórica que ha caracterizado a la confrontación interna colombiana" (Corte Constitucional, 2012a). Para la alta Corporación, debe rechazarse una concepción estrecha de conflicto armado, que: "(i) se limita a un conjunto específico de acciones y actores armados, (ii) se caracteriza por el uso de ciertas armas y medios de guerra, o, (iii) se circunscribe a áreas geográficas específicas" (Corte Constitucional, 2012a).

El tercer aspecto relevante es la aplicación de criterios de protección de las víctimas. En esta dirección, se asimilan tres universos de casos. En un primer grupo, existirán elementos determinantes para afirmar con un mayor grado de certeza que se está ante una conducta realizada con ocasión del conflicto armado. Un segundo grupo consagra criterios objetivos que permiten excluir ciertas conductas como no relacionadas con el conflicto armado. Finalmente, un tercer grupo, relativo a eventos en los que será imposible indicar de antemano si se guarda relación con el conflicto, pero que tampoco podrá ser excluida, sin más. La Corte llama a estos casos "zona gris" (Corte Constitucional, 2012b).

En suma, se tiene que, para este tribunal, el tipo de actor no es el aspecto determinante para establecer si se asiste a un crimen común o a un crimen de guerra. De acuerdo con la Corte:

\begin{abstract}
La condición de conflicto armado tiene lugar cuando los hechos acaecidos guardan una relación de conexidad suficiente con este, sin que sea posible establecer límites al concepto de conflicto armado, entre otros factores, a partir de la calidad o condición específica del sujeto que cometió el hecho victimizante. (Corte Constitucional, 2016a).
\end{abstract}

Se requiere, por tanto, analizar en cada caso concreto si el accionar de un grupo armado constituyó un crimen atentatorio de las personas y bienes protegidos por el DIH o de un crimen común. Para ello, de acuerdo con la Corte, se atiende a las nociones amplias de conflicto armado y de víctima.

\section{LA CONGRUENCIA PROCESAL EN SUS VERTIENTES PERSONAL, FÁCTICA Y JURÍDICA: POSIBILIDADES DE MODIFICACIÓN DE LA CONGRUENCIA EN SENTIDO JURÍDICO}

De acuerdo con el texto constitucional, la autoridad encargada de investigar las conductas que revistan el carácter de delito es la Fiscalía General de la Nación. Por ende, a esta institución se encomien- 
da esclarecer en la fase investigativa del proceso penal si, en los casos concretos, se trata de crímenes comunes o crímenes de guerra. En la etapa del juzgamiento, deberá demostrar la pretensión elevada en el pliego de cargos.

Sin perjuicio de estas funciones, y de acuerdo con el modelo de Estado social de derecho, esta investigación de la criminalidad no puede llevarse a cabo de cualquier forma. Deben salvaguardarse las garantías fundamentales de las personas sometidas a la potestad punitiva del Estado y de los demás intervinientes, especialmente de las víctimas.

Dentro de este conjunto de principios se encuentra la congruencia procesal, es decir, la consonancia entre la acusación y la sentencia (Bazzani, 2016). Ello al tenor de lo reglado en el artículo 448 del Código de Procedimiento Penal.

Se tiene establecido que la congruencia puede ser fáctica, personal y jurídica (Corte Suprema de Justicia, Sala de Casación Penal, 2011). De igual forma, la jurisprudencia señala que la congruencia en sus vertientes fáctica y personal es inamovible a lo largo de la actuación. Debe garantizarse que el sujeto pasivo de la acción penal tenga certeza de que sobre él se ejerce la potestad penal —congruencia personal-, por unos determinados hechos que motivan el llamamiento a juicio — congruencia fáctica-. De allí se desprende la necesidad de que estos aspectos no sufran varianza a lo largo de la actuación (Corte Suprema de Justicia, Sala de Casación Penal, 2014b).
A su turno, la congruencia en su vertiente jurídica no corre la misma suerte. Puede sufrir variaciones en la actuación. Ello no implica, sin embargo, que puede modificarse de manera libérrima por parte del acusador o del fallador. Por el contrario, se trata de una actividad procesal reglada (Mendoza, 2009). Por ende, el juzgador puede condenar por una conducta que se encuentre prevista en el mismo título del Código Penal, y que además contemple una sanción menos rigurosa (Corte Suprema de Justicia, Sala de Casación Penal, 2014a).

De acuerdo con el estatuto adjetivo, una persona no puede recibir condena por hechos respecto de los que no se formuló acusación. Prima facie, es necesaria la correspondencia entre la conducta por la cual se sucede el llamamiento a juicio y aquella por la que finalmente es condenado el procesado. Sin perjuicio de ello, y toda vez que el proceso es una construcción paulatina de conocimiento, no son inusuales las falencias respecto del nomen iuris al que se adecuan los hechos por los que la persona es acusada.

No sería insólito que, al término del juzgamiento, el fallador encuentre que el punible por el que el acusado fue llamado a juicio no es el que se demostró en el juicio. De acuerdo con la posibilidad de modificación de la congruencia jurídica, el juez puede condenar por una conducta diferente de la consignada en el pliego de cargos, siempre que se reúnan las condiciones de ubicación capitular de la conducta y sanción más benigna para el acusado. 


\section{LA COMPETENCIA POR EL FACTOR OBJETIVO -NATURALEZA DEL ASUNTO - EN LOS CASOS DE LOS DELITOS CONTRA LAS PERSONAS Y BIENES PROTEGIDOS POR EL DERECHO INTERNACIONAL HUMANITARIO}

De acuerdo con el artículo 35 de la Ley 906 de 2004, la competencia para conocer de los crímenes de guerra, esto es, de los delitos contra las personas y bienes protegidos por el derecho internacional humanitario, se atribuye al juez penal del circuito especializado. De manera que la norma aplica el criterio objetivo por la naturaleza del asunto. De los delitos que no tengan asignación especial de competencia conocerá el juez penal del circuito, al tenor del artículo 36 de la misma normativa.

Se recuerda que el factor objetivo de la competencia se determina por la naturaleza del asunto o por la cuantía - que en la jurisdicción penal no tiene relevancia-. De acuerdo con la Corte Constitucional, el factor objetivo de competencia "también ha sido nominado por razón del litigio o la materia y es aquel criterio que sirve para especializar las áreas de la jurisdicción: penal, civil, administrativa, etc., por eso es llamada en razón al litigio dada por el proceso y la cuantía" (Corte Constitucional, 2014).

En cuanto a los delitos contra las personas y bienes protegidos por el DIH, el criterio que se acoge es, evidentemente, el de la naturaleza del asunto. Para la doctrina, este criterio alude:

\begin{abstract}
Al contenido de la pretensión, razón por la cual se le conoce también como la competencia por razón de la materia, pues atendiendo exclusivamente al tipo de controversia que se ventila se le atribuye la competencia a un determinado juez sin tener en cuenta ningún otro tipo de consideración. (Sanabria Santos, 2014, p. 20).
\end{abstract}

De acuerdo con Hernando Devis (1966), el factor objetivo por la naturaleza del asunto "contempla ciertos caracteres del negocio o litigio distintos de su valor, del territorio, de las funciones especiales desempeñadas por el juez en el proceso (factor funcional) y de la calidad peculiar de las partes (factor subjetivo)" (p. 111).

\section{PROBLEMÁTICAS DERIVADAS DEL PRINCIPIO DE CONGRUENCIA Y LA COMPETENCIA POR EL FACTOR OBJETIVO EN LOS CASOS DE CRIMENES DE GUERRA COMETIDOS POR LOS MIEMBROS DE LAS AGRUPACIONES DE CRIMEN ORGANIZADO}

La competencia en materia penal se determina, esencialmente, mediante la presentación del escrito de acusación. En esta actuación se efectúa la imputación jurídica circunstanciada, y a partir de allí se predica la congruencia entre la acusación y el fallo. Si el fiscal acusa por un delito común, la competencia recaerá en los jueces penales municipales, en los jueces penales del circuito o en los jueces penales del circuito especializado, según sea el caso. Pero si la acusación versa sobre un delito contra las personas y bienes 
protegidos por el DIH, la competencia recaerá necesariamente en el juez penal del circuito especializado, y es por ello que se afirma en este escrito que el problema de la congruencia jurídica tiene relación con la determinación de la competencia por la naturaleza del asunto.

Sin embargo, conforme el artículo 43 del Código de Procedimiento Penal, solamente se permite a las partes controvertir la competencia del juez en la audiencia de acusación, pues de no haber controversia, la competencia se entiende prorrogada. Con todo, la proposición jurídica completa se integra con el predicamento del artículo 456 de la Ley 906 de 2004. De acuerdo con esta norma, habrá lugar a la nulidad si la competencia para el asunto corresponde en realidad al juez penal del circuito especializado.

Supóngase entonces el evento en que debía acusarse por un delito contra las personas y bienes protegidos por el DIH y, no obstante, por una falencia en la etapa de investigación, se elabora el pliego de cargos por un crimen común, que tenga competencia radicada en juez distinto al penal del circuito especializado. Si en este evento la competencia no se controvierte en la etapa de acusación, el juez a la hora de dictar el fallo se enfrenta a un serio dilema, y cuenta con las siguientes posibilidades:

i) Puede condenar por el punible por el que se llamó al acusado a juicio. No podría el juez condenar por el delito contra las personas y bienes protegidos por el derecho internacional humanitario, pues atentaría contra el principio de congruencia.

ii) Puede decretar oficiosamente la nulidad de la actuación, de acuerdo con la regla prevista en el artículo 456 de la Ley 906 de 2004. Este decreto puede tener lugar en cualquier etapa posterior a la acusación y antes de proferir sentencia. Si el juzgador advierte el error en la calificación jurídica, ordena que se retrotraiga la actuación hasta el escrito de acusación, con la finalidad de que se adecue al nomen iuris violatorio de los delitos contra las personas y bienes protegidos por el DIH. Ello implica, por fuerza, la modificación de la competencia, pues el criterio determinante es el factor objetivo por la naturaleza del asunto.

En todo caso, lo que aparece claro procesalmente es que el juez no puede condenar en la sentencia por un crimen de guerra, si es que en el pliego de cargos se acusó por un delito común, ya que no pertenecen al mismo título del Código Penal y porque, eventualmente, el crimen de guerra contendrá una pena más severa que la del delito común. Cada una de estas eventualidades ofrece consideraciones de importancia. En efecto:

En una primera posibilidad, el juez condena por el delito por el que la persona fue llamada a juicio, aunque la realidad fáctica arroje que se trata de un crimen contra las personas y bienes protegidos por el derecho internacional humanitario. En este evento, el acusado obtendrá un inmerecido beneficio, que colisiona 
con los derechos de las víctimas, especialmente el derecho a la justicia. La actuación del Estado debe imponer las correlativas sanciones a los infractores. Por ello, no aparece materialmente justo que se condene por un delito con pena menor. Paradójicamente, en este caso no se vulneraría el principio de congruencia, pues se condena por el mismo delito por el que se elevó el pliego de cargos. No obstante, esta solución conduce a la aludida vulneración de los derechos de las víctimas.

En una segunda posibilidad, el juez declara la nulidad de la actuación a partir de la presentación del escrito de acusación, con la finalidad de que se adecue a derecho, mediante la determinación clara de la congruencia jurídica. Al modificarse el nomen iuris de la conducta, necesariamente se modifica la competencia, que recaerá en el juez penal del circuito especializado. Esta posibilidad acarrea igualmente problemáticas, por cuanto:

i) La Fiscalía es la entidad titular de la acción penal, y la actuación del juez podría significar una invasión en la competencia del ente acusador que, en tanto dueño de la acusación, determina el nomen iuris por el que se convocará a la persona procesada al juicio.

ii) De otra parte, es aún más problemático aceptar que los errores cometidos por el Estado en ejercicio de la potestad punitiva pueden ser cargados al procesado. La declaratoria de nulidad implica, en la práctica, una nueva oportunidad para que el Estado enmiende sus errores y realice nuevamente las etapas de acusación y juzgamiento, con impacto en los derechos fundamentales de los acusados.

¿Cómo resolver el conflicto entre estas dos posibilidades? Desde este escrito, se plantea como la solución más adecuada la declaratoria de la nulidad. Debe ordenarse que se rehaga la actuación desde la presentación del pliego de cargos, por las siguientes razones:

Si se atiende al concepto amplio de conflicto armado, la urdimbre entre la criminalidad organizada y el conflicto genera dificultades a la hora de tipificar adecuadamente las conductas. Con todo, en caso de duda debe prevalecer la situación que genere mayor cobertura para los derechos de las víctimas (Corte Constitucional, 2017).

Esta protección de los derechos de las víctimas se hace necesaria en virtud de la adopción del paradigma de la justicia restaurativa en el proceso penal colombiano (Gaviria, 2011). El enjuiciamiento criminal deja de percibirse como un conflicto que se sucede únicamente entre el acusado y el Estado (Maier, 1992). La necesidad de garantizar los derechos fundamentales de las víctimas a la verdad, la justicia y la reparación integral conduce a que el proceso en sí mismo deba analizarse como un espacio de desvictimación (Sampedro, 2010).

En otro pronunciamiento, manifestó la Corte que: 
Esto es, probada la existencia de una afectación grave de derechos humanos o de una infracción de las normas del derecho humanitario, en caso de duda sobre la inserción de la conducta lesiva en el marco del conflicto, debe darse prevalencia a la interpretación en favor de la víctima. (Corte Constitucional, 2016b).

Por tanto, debe prestarse atención a la realidad misma de los hechos jurídicamente relevantes. Es decir, si la hipótesis investigada se corresponde con un crimen de guerra, es por dicha figura por la que debe surtirse la actuación. Ello genera de suyo la incompetencia del juez que conoce, y habrá de acudirse en consecuencia a la declaratoria de nulidad.

Debe acudirse a la noción amplia de víctimas. De acuerdo con las previsiones de la jurisprudencia constitucional, es necesario acudir a las determinaciones que más las favorezcan, con dependencia de la realidad de los sucesos concretos. Como se propone, la condena por un delito común impacta negativamente el derecho a la justicia de las víctimas. Por consiguiente, es razonable entender que la solución más adecuada es la declaratoria de nulidad.

Debe insistirse en que esta problemática de la competencia no es un prurito formalista. Con esta institución se realizan los principios de juez natural y el debido proceso, ambos de relevancia constitucional. Toda la estructura de la rama judicial atiende al cumplimiento de este axioma. La especialización de la jurisdicción realiza la seguridad jurídica, pues prevé que el juez competente sea el juez especializado en determinados asuntos.

En los eventos de delitos contra las personas y bienes protegidos por el DIH se halla en juego el debate sobre graves violaciones de derechos humanos. Por ende, se requiere la mayor atención del Estado en la solución del conflicto, especialmente cuando los sujetos activos del crimen de guerra son miembros de organizaciones criminales, que se hallan inmersas en la vorágine de relaciones con el conflicto armado.

\section{CONCLUSIONES}

La posición de la jurisprudencia de la Corte Constitucional relativa a la necesidad de establecer caso por caso los tipos de crímenes que pueden cometer las agrupaciones de delincuencia organizada debe saludarse con beneplácito, puesto que supera las consideraciones respecto de la naturaleza del grupo como instancia previa al establecimiento de los tipos de crímenes que realicen. En ello, se insiste, la Corte hace eco de la posición actual de derecho internacional humanitario (Defensoría del Pueblo, 2014).

Con las decisiones de la Corte Constitucional analizadas, queda claro que un grupo de criminalidad organizada puede ser sujeto activo de delitos contra las personas y bienes protegidos por el derecho internacional humanitario, ya sea que su naturaleza se derive del accionar de los grupos paramilitares o no. Los puntales para esta determinación son, como se vio, la noción amplia de conflicto armado y el 
concepto amplio de víctima. Estos institutos representan criterios hermenéuticos favorables al contexto de los instrumentos internacionales suscritos y ratificados por Colombia y los derechos fundamentales de las víctimas.

Ahora bien, estos criterios hermenéuticos llevan a que, en la práctica, existan dificultades en su aplicación. A efectos de este escrito, se tomó el universo de casos que son competencia de los jueces penales del circuito especializado, es decir, en aplicación del factor objetivo de competencia por la naturaleza del asunto, cuando se trata de los delitos contra las personas y bienes protegidos por el derecho internacional humanitario, que son siempre competencia del juez penal del circuito especializado.

Las falencias en la actividad investigativa pueden conducir a que se llame a juicio por un delito común, cuando debía acusarse por un crimen de guerra. En este evento, surgen dos posibilidades: i) que el juez condene por el delito común, evidenciándose en este caso un impacto negativo en los derechos de las víctimas, especialmente en el derecho a la justicia; ii) que el juez decrete la nulidad, en seguimiento de la regla prevista en el artículo 456 del Código de Procedimiento Penal, que permite dicha declaratoria cuando el asunto corresponde a la competencia del juez penal del circuito especializado.

Así, la tesis central que se adoptó en el presente artículo es que en estos casos la solución que mejor se adapta a las necesidades de justicia material y los derechos de las víctimas es la declaratoria de la nulidad. Esta solución —aunque presta buen favor a los derechos de las víctimas, la conservación del principio de juez natural y al seguimiento de las reglas hermenéuticas fijadas por la Corte Constitucional — no deja de impactar en el peso que soportará el miembro del grupo de criminalidad organizada al que se someta a potestad punitiva, pues habrá de cargar con las falencias cometidas por el ente acusador.

\section{REFERENCIAS}

Amnistía Internacional. (2016). Informe 2015/16 Amnistía Internacional. La situación de los Derechos Humanos en el mundo. Recuperado de https:// www.amnesty.org/download/Documents/ POL1025522016SPANISH.PDF

Arias, A. (2011). Neoparamilitares-Bacrim: acciones de interferencia para las elecciones locales de 2011. En Grupo técnico mapas de riesgo electoral. MOE (Realizadores), Mapas y factores de riesgo electoral: elecciones locales y regionales, octubre 2011 (pp. 250-255). Bogotá: Corporación Nuevo Arco Iris.

Bazzani, D. (2016). El principio de congruencia y la variación de la calificación en el proceso penal colombiano: propuesta de solución. Ponencia. Recuperado de https://www.acj.org.co/ images/descargas/trabajos _ academicos/ Ponencia-Dario-Bazzani.pdf

Comisión Interamericana de Derechos Humanos. (2013). Denuncias de violaciones de derechos humanos cometidas por paramilitares en Colombia. Audiencia en el $149^{\circ}$ periodo ordinario de sesiones, 31 de octubre de 2013.

Congreso de la República. (2004). Ley 906 de agosto 31 por la cual se expide el Código de Procedimiento Penal. Diario Oficial 45 657. Bogotá. 
Corte Constitucional. (2012a). Sentencia C-781 de octubre 10. M.P. Calle Correa, M.

Corte Constitucional. (2012b). Sentencia C-253A de marzo 29. M.P. Mendoza Martelo, G.

Corte Constitucional. (2014). Sentencia T-308 de mayo 28. M.P. Pretelt Chaljub, J.

Corte Constitucional. (2016a). Sentencia C-069 de febrero 18. M.P. Guerrero Pérez, L.

Corte Constitucional. (2016b). Sentencia T-290 de junio 2. M.P Rojas Ríos, A.

Corte Constitucional. (2017). Sentencia T-163 de marzo 13. M.P. Ortiz Delgado, G.

Corte Suprema de Justicia. Sala de Casación Penal. (2011). Rad. 34.022 de junio 8. M.P. Socha Salamanca, J.

Corte Suprema de Justicia. Sala de Casación Penal. (2014a). Rad. 38.725 de enero 22. M.P. Fernández Carlier, E.

Corte Suprema de Justicia. Sala de Casación Penal. (2014b). Rad. 40.409 de noviembre 6. M.P. Patiño Cabrera, E.

Defensoría del Pueblo. (2014) ¿Qué es el Derecho Internacional Humanitario? Recuperado de http://campusvirtual.defensoria.gov.co/ wp-content/uploads/2016/10/Que-es-elderecho-internacional-humanitario.pdf

Departamento Federal de Asuntos Exteriores. (2014). El ABC del Derecho Internacional Humanitario. Recuperado de https://www. eda.admin.ch/dam/eda/es/documents/ publications/GlossarezurAussenpolitik/ABCHumanitaeren-Voelkerrechts _ es.pdf

Devis Echandía, H. (1966). Nociones generales de derecho procesal civil. Madrid: Aguilar.

Echandía Castilla, C. (2013). Narcotráfico: génesis de los paramilitares y herencia de bandas criminales. Fundación Ideas para la Paz. Informes FIP, (19). Bogotá.

Garzón, J. (2008). Mafia y Co. La red criminal en Ciudad de México, Brasil y Colombia. Bogotá: Planeta.
Gaviria Londoño, V. (2011). Victimas, acción civil y

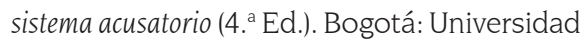
Externado de Colombia.

Granada, S., Restrepo, J. y Tobón García, A. (2009). Neoparamilitarismo en Colombia: una herramienta conceptual para la interpretación de dinámicas recientes del conflicto armado colombiano. En J. Restrepo y D. Aponte (Eds.), Guerra y violencias en Colombia: herramientas e interpretaciones (pp. 467-

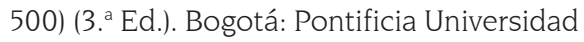
Javeriana.

Kessler, G. (2014). Crimen organizado en América Latina y el Caribe: ejes de debate sobre narcotráfico, tráfico de armas y de personas. En Z. Betancur y J. Alfredo. (coords.), El laberinto de la inseguridad ciudadana: bandas criminales, seguridad de fronteras y regímenes penitenciarios en América Latina (pp. 17-38). Buenos Aires: Universidad Autónoma de Ciudad Juárez y CLACSO.

Latorre Iglesias, E. y Arregocés, F. (2014). Caracterización de la formación y estructuración de las bandas criminales en el Departamento del Magdalena. Advocatus, 11 (22), 261-279.

Maier, J.B. (1992). La víctima y el sistema penal. En J. Maier (Ed.), De los delitos y de las víctimas (pp. 147-173). Buenos Aires: Ad-Hoc.

Mendoza Díaz, J. (2009). La correlación entre la acusación y la sentencia: una visión americana. Revista del Instituto de Ciencias Jurídicas de Puebla, (24), 149-171.

Organización de las Naciones Unidas. (2011). Protección jurídica internacional de los derechos humanos durante los conflictos armados. Recuperado de http://www.cdih.gob.pe/ cdih/wp-content/uploads/2017/02/1.-DH conflictos _ armados.pdf

Pérez Salazar, B. y Montoya Cely, C. (2013). Las Bacrim después de 2013: ¿pronóstico reservado? Informe de investigación a diciembre de 2013. Bogotá: Fundación Paz y Reconciliación. Recuperado de http://www.pares.com.co/ 
wp-content/uploads/2013/12/Informe-2013Bacriml.pdf

Prieto, C. (2012). Bandas criminales en Colombia: ¿amenaza a la seguridad regional? Ópera, (12), 181-204.

Prieto, C. (2013). Las Bacrim y el crimen organizado en Colombia. Friedrich Ebert Stiftung. Programa de Cooperación en Seguridad Regional. Bogotá. Recuperado de http://library.fes. de/pdf-files/bueros/la-seguridad/09714.pdf

Rico, D. (2013). La dimensión internacional del crimen organizado en Colombia: las Bacrim, sus rutas y refugios. Wilson Center, Latin American Program. Washington. Recuperado de https://www.wilsoncenter.org/sites/default/ files/Daniel\%20Rico.pdf

Salmón, E. (2012). Introducción al Derecho Internacional Humanitario. Comité Internacional de la Cruz Roja. Lima: Cruz Roja.

Sampedro Arrubla, J. (2010). Las víctimas y el sistema penal: aproximación al proceso penal desde la victimología. Bogotá: Pontificia Universidad Javeriana.

Sanabria Santos, H. (2014). Factores de atribución de la competencia de los jueces civiles en el Código General del Proceso. Recuperado de https:// letrujil.files.wordpress.com/2013/09/01henrysanabria.pdf 